\title{
Isotopic Germanium Targets for High Beam Current Applications at GAMMASPHERE*
}

\author{
John P. Greene and Torben Lauritsen
}

\author{
Physics Division, Argonne National Laboratory, 9700 S. Cass Avenue, Argonne, IL 60439 USA
}

\begin{abstract}
The creation of a specific heavy ion residue via heavy ion fusion can usually be achieved through a number of beam and target combinations. Sometimes it is necessary to choose combinations with rare beams and/or difficult targets in order to achieve the physics goals of an experiment. A case in point was a recent experiment to produce ${ }^{152}$ Dy at very high spins and low excitation energy with detection of the residue in a recoil mass analyzer. Both to create the nucleus cold and with a small recoil-cone so that the efficiency of the mass analyzer would be high, it was necessary to use the ${ }^{80} \mathrm{Se}$ on ${ }^{76} \mathrm{Ge}$ reaction rather than the standard ${ }^{48} \mathrm{Ca}$ on ${ }^{108} \mathrm{Pd}$ reaction. Because the recoil velocity of the ${ }^{152} \mathrm{Dy}$ residues was very high using this symmetric reaction $(5 \% \mathrm{v} / \mathrm{c})$, it was furthermore necessary to use a stack of two thin targets to reduce the Doppler broadening. Germanium targets are fragile and do not withstand high beam currents, therefore the ${ }^{76} \mathrm{Ge}$ target stacks were mounted on a rotating target wheel. A description of the ${ }^{76} \mathrm{Ge}$ target stack preparation will be presented and the target performance described.
\end{abstract}

\section{Introduction and Motivation}

In order to search for hyperdeformation as well as linking transitions from superdeformed bands in the mass 150 region, an investigation of the decay quasicontinuum $\gamma$ rays in the nuclei ${ }^{151.152}$ Dy was needed. Sufficient statistics were required to extract and determine the character of the decay out as well as $\gamma$ rays emitted while the nucleus is potentially hyperdeformed. This was accomplished using the reaction ${ }^{76} \mathrm{Ge}\left({ }^{80} \mathrm{Se}, 5 \mathrm{n} 14 \mathrm{n}\right){ }^{1511152} \mathrm{Dy}$ and GAMMASPHERE [1] with the Fragment Mass Analyzer (FMA) [2]. The ATLAS accelerator was used to provide as much beam on target as allowed by the counting rates in GAMMASPHERE. Earlier experiments with fixed targets showed severe target damage due to re-crystallization which prompted the use of a rotating ${ }^{76} \mathrm{Ge}$ target wheel. Thin targets were needed to reduce the amount of Doppler broadening observed in the emitted $\gamma$ rays. The $400 \mu \mathrm{g} / \mathrm{cm}^{2}$ thickness of the ${ }^{76} \mathrm{Ge}$ target was chosen to reduce the number of normal decay $\gamma$ rays in the decay out region in ${ }^{151.152}$ Dy by taking advantage of isomers in the nuclei. To further optimize the experiment, a double stack of $400 \mu \mathrm{g} / \mathrm{cm}^{2}{ }^{76} \mathrm{Ge}$ targets was employed. This stacking of targets is a common experimental technique to reduce Doppler broadening without reducing yield, however it has never before been attempted with target wheels rotating at 600 RPM.

*Work supported by the U.S. Department of Energy, Nuclear Physics Division, contract No. W-31-109-ENG-38.
The crystalline nature of elemental germanium is a challenge for the production of freestanding foils for use in experiments with heavy-ion beams. Many techniques are available including centrifugation, vaporization using electron bombardment, and deposition employing electron beam or focused ion beam sources. A detailed listing of the various methods for the preparation of germanium films has been given by Meens and Ehret [3]. For our purposes, we employed vacuum deposition using a multi-pocket electron beam source of $270^{\circ}$ geometry [4].

\section{Germanium Targets}

The ${ }^{76} \mathrm{Ge}$ separated isotope needed for the targets was obtained as an oxide from Oak Ridge National Laboratory (ORNL) and had an enrichment of $92.82 \%$. The oxide was reduced to the metallic form using a hydrogen furnace $[5,6]$. The deposition was carried out using an electron beam source onto standard microscope slides, as described by Meens and Ehret [3]. The slides were first coated with $\mathrm{NaCl}$ as a parting agent immediately beforehand, using the same source. Although Ramsay [7], recommends $\mathrm{BaCl}$ as the optimum substrate for germanium film growth, we experienced difficulty with release of the foils using this salt. The source to substrate distance was $10 \mathrm{~cm}$. The glass slides were heated to approximately $215^{\circ} \mathrm{C}$ using a quartz lamp. This temperature was arrived at empirically from previous preparations of Ge targets. The pressure within the evaporator was $2 \times 10^{-6}$ torr, provided by a cryopump. The ${ }^{76} \mathrm{Ge}$ films were then 


\section{DISCLAIMER}

This report was prepared as an account of work sponsored by an agency of the United States Government. Neither the United States Government nor any agency thereof, nor any of their employees, make any warranty, express or implied, or assumes any legal liability or responsibility for the accuracy, completeness, or usefulness of any information, apparatus, product, or process disclosed, or represents that its use would not infringe privately owned rights. Reference herein to any specific commercial product, process, or service by trade name, trademark, manufacturer, or otherwise does not necessarily constitute or imply its endorsement, recommendation, or favoring by the United States Government or any agency thereof. The views and opinions of authors expressed herein do not necessarily state or reflect those of the United States Government or any agency thereof. 


\section{DISCLAIMER}

Portions of this document may be illegible in electronic image products. Images are produced from the best available original document. 
floated off and eight quadrant targets were prepared with thicknesses of $300-400 \mu \mathrm{g} / \mathrm{cm}^{2}$, enough for one double stacked target wheel.

\section{GAMMASPHERE Target Wheel}

In order to withstand the high beam currents necessary for the experiment, the targets were prepared as a rotating target wheel. The GAMMASPHERE target wheel was developed for use with volatile or low melting point target materials and has been described previously $[8,9]$. The targets were mounted on four quadrant frames, each with an open area of $2.62 \mathrm{~cm}^{2}$. This allows for the higher beam power to be dissipated over a larger area. With the addition of beam wobbling in the vertical direction, so as not to degrade the mass resolution of the FMA, the power per unit area deposited in the target is substantially reduced, thus lowering the temperature within the target. As can be shown from previous calculations [10], the calculated power per unit area deposited in the rotating wheel target for the $314 \mathrm{MeV}$ ${ }^{80} \mathrm{Se}$ beam with a current of $5 \mathrm{pnA}$ was $7.15 \mathrm{~mW} / \mathrm{cm}^{2}$. This translates to a temperature within the target of about $99^{\circ} \mathrm{C}$. This is to be compared with a calculated temperature of $488^{\circ} \mathrm{C}$ for a non-rotating target. In Figure 1, a plot of the time dependence of the heating within the target is given for the first 10 revolutions of the wheel. This heating from the beam would remain well below the melting point of $938.3^{\circ} \mathrm{C}$ for germanium, thus avoiding loss of target material and increasing the target lifetime.

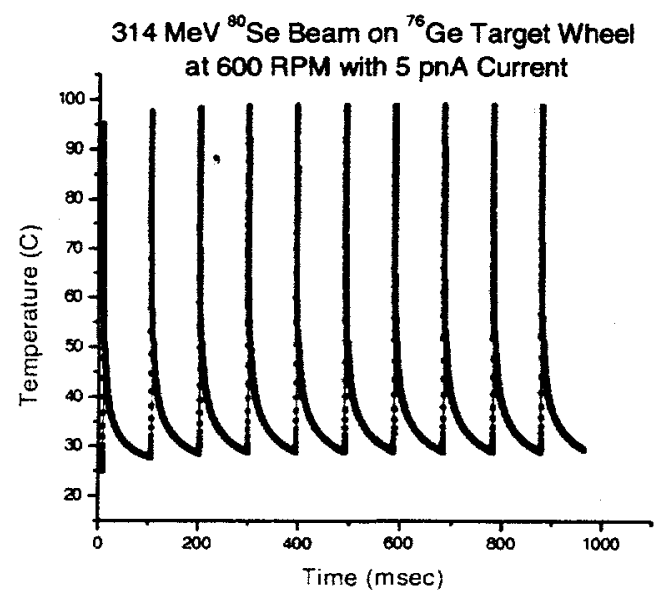

FIGURE 1. Plot of Temperature vs. Time showing the time dependence of the target heating over the first 10 revolutions of the target wheel.

\section{Results and Conclusion}

OSTI

In conclusion, the preparation of isotopic germanium target wheels for GAMMASPHERE proved crucial to the success of the experiment. A double stack of $300-400 \mu \mathrm{g} / \mathrm{cm}^{2}{ }^{76} \mathrm{Ge}$ foils, prepared for a rotating target wheel, provided sufficient ${ }^{151,152} \mathrm{Dy}$ reactions for the experiment and withstood $314 \mathrm{MeV}$ ${ }^{80} \mathrm{Se}$ beam currents of $5 \mathrm{pnA}$ for six days of running. Examination of the target wheels after irradiation revealed severe damage due to re-crystallization within the foil, particularly for the front foil stack, facing the beam. The re-crystallization temperature for germanium occurs somewhere between $90^{\circ}$ and $454^{\circ} \mathrm{C}$ which would indicate that the target was exposed to a deposited beam power greater than that calculated. This suggests that the focused beam spot may be smaller than expected. A photograph is given in Figure 2 showing target quadrants before and after bombardment by the heavy ion beam.
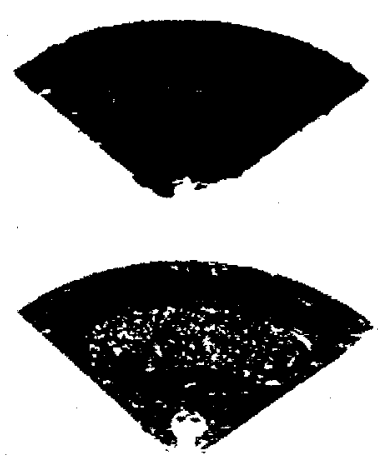

Figure 2. Photograph of ${ }^{76} \mathrm{Ge}$ target wheel quadrants before and after bombardment by 5 pnA $314 \mathrm{MeV}{ }^{80}$ Se beam showing damage due to recrystallization in the target.

\section{Acknowledgments}

The authors would like to thank Dr. Donald Geesaman, the Physics Division Director, and Dr. Irshad Ahmad, the Target Facility Group Leader, for their continuing encouragement and support of these efforts. This work is supported by the U.S. Department of Energy, Nuclear Physics Division, under Contract No.W-31-109-Eng-38. 


\section{References}

[1] L.Y. Lee, et al., Nucl. Instr. and Meth. A520 (1990) p. $641 \mathrm{c}$

[2] C.N. Davids, et al., Nucl. Instr. and Meth. B70 (1992) p. 358

[3] A. Meens and G. Ehret, Nucl. Instr. and Meth. in Phys. Res. A362 (1995) 53-59

[4] G.E. Thomas, J.P. Greene, P. Maier-Komor and R.H. Leonard, Nucl. Instr. and Meth. in Phys. Res. A303 (1991) 162-164

[5] J.M. Heagney and J.S. Heagney, Proc. Conf. INTDS, Report LA-6850-C Los Alamos, NM (1977) p. 92

[6] H.U. Friebel, D. Frischke, R. Grossman and H.J. Maier, Nucl. Instr. and Meth. 167 (1979) 9-11

[7] D. Ramsay, Proc. Conf. INTDS, Chalk River, Canada (1974) p. 151

[8] J. P. Greene, G.E. Thomas and R.H. Leonard, Nucl. Instr. and Meth. in Phys. Res. A362 (1995) 81-89

[9] J.P. Greene, et al., Applications of Accelerators in Research and Industry, J.L. Duggan and I.L. Morgan (eds.), The American Institute of Physics, CP475 (1999) 929-931

[10] J.P. Greene, R. Gabor and J. Neubauer, in preparation

\footnotetext{
The submitted manuscript has been created by the University of Chicago as Operator of Argonne National Laboratory ("Argonne") under Contract No. W-31-109-ENG-38 with the U.S. Department of Energy. The U.S. Government retains for itself, and others acting on its behali, a paid-up, nonexclusive, irrevocable worldwide license in said article to reproduce, prepare derivative works, distribute copies to the public, and perform publicly and display publicly, by or on behalf of the Government.
} 